Article

\title{
Adolescents' Exposure to Online Risks: Gender Disparities and Vulnerabilities Related to Online Behaviors
}

\author{
Elena Savoia, $1,2, *$ Nigel Harriman, ${ }^{1}$ Max Su, ${ }^{1,2}$ Tyler Cote, ${ }^{3}$ and Neil Shortland ${ }^{4}$ \\ ${ }^{1}$ Emergency Preparedness, Research, Evaluation, and Practice Program, Division of Policy Translation and Leadership \\ Development, Harvard T.H. Chan School of Public Health, Boston, MA 02115, USA \\ 2 Department of Biostatistics, Harvard T.H. Chan School of Public Health, Boston, MA 02115, USA \\ ${ }^{3}$ Operation 250, Lowell, MA 01854, USA \\ ${ }^{4}$ Center for Terrorism and Security Studies, University of Massachusetts Lowell, Lowell, MA 01854, USA \\ *Author to whom correspondence should be addressed: preparedness@hsph.harvard.edu
}

\begin{abstract}
In the last decade, readily available electronic devices have created unprecedented opportunities for teens to access a wide variety of information and media - both positive and negative - on the internet. Despite the increasing number of initiatives taking place worldwide intended to assess and mitigate the online risks encountered by children and adolescents, there is still a need for a better understanding of how adolescents use the internet and what consequences they may face. We conducted a cross sectional online survey of a convenience sample of 733 8th and 9th grade students in Utah. The survey contained eight questions regarding students' exposure to three types of online risk scenarios: content risk, contact risk, and commercial risk. Independent variables included students' online behaviors, use of social media and private messaging apps, and adult supervision of online activities. Logistic and negative binomial regression models indicated that female gender, social media use, and chatting with strangers were associated with exposure to multiple unsafe online scenarios. Our results provide critical information to practitioners involved in the development of educational initiatives by building a profile of potentially risky online behaviors and allow them to tailor their initiatives to meet the needs of more vulnerable populations.
\end{abstract}

Keywords: Online Safety; Online Risk; Online Behaviors; Gender Disparities; High School Students; Social Media

\section{Introduction}

In the last decade, readily available electronic devices such as computers, tablets, and smartphones have created unprecedented opportunities for teens to communicate, connect, share, and access a wide variety of information and media on the internet ${ }^{1,2}$. A 2018 survey reported that nearly all U.S. teens (95\%) have access to a smartphone and $45 \%$ are "almost constantly" on the internet. Information and communication technologies are playing a key role in fulfilling adolescents' emotional and communication needs ${ }^{3}$, and the instrumental and social functions of such technologies are having a critical impact on teens' interactions with parents, peers, and social groups ${ }^{4}$. Digital communication can both strengthen and strain teen-parent relationships. Mobile phones provide a permanent channel of communication between parents and teenagers, thereby offering opportunities to intensify parental supervision and control ${ }^{5-7}$. However, the same technology is also facilitating the process by which teens connect with peers and with individuals in an independent manner free from parental surveillance.

Despite the increasing number of initiatives taking place worldwide intended to assess and mitigate the online risks encountered by children and adolescents, there is still a need for a better understanding of how adolescents use the internet and what consequences they may face 2,8 . The current understanding of how young people experience communication technologies, how they perceive opportunities for risks over the internet, and how social media shapes their interactions is developing but admittedly incomplete. 


\subsection{Adolescents' exposure to risky online situations}

Risky online situations that adolescents may encounter have been classified into three groups: 1) "content risk", referring to user exposure to possible harmful contents, 2) "contact risk", referring to user activities and communications with known or unknown individuals that carry a potential threat and 3) "commercial risk", referring to situations in which commercial organizations attempt to exploit the user ${ }^{9}$. As a highly interactive platform, social media facilitates more opportunities for adolescents to engage in risky behaviors. When online, adolescents devote much of their free time to social media, using social media platforms for an average of nearly 3 hours each day ${ }^{10,11}$. Understanding the relationship between social media use and risky behaviors during adolescence is crucial given the increased propensity for risk-taking that is unique to this developmental period ${ }^{12,13}$. Several studies and reviews of existing literature provide evidence illustrating how the use of social media impacts - both positively and negatively - essential aspects of adolescents' mental health and psychosocial development, including self-esteem, social connectedness, peer communications ${ }^{14-16}$, and how social media may pose risks of cyber victimization and lurking 17-20. A recent meta-analysis showed that higher levels of social media use among adolescents are associated with more frequent engagement in the use of drugs, risky sexual acts, and violent behaviors with a small-to-medium magnitude of effect ${ }^{21}$. Specific examples of negative situations experienced by adolescents in the online space include: being contacted by a stranger, having either seen or received media that made them feel uncomfortable, having felt under pressure to send photos or other information about themselves, and having accidentally spent money online that they did not mean to spend ${ }^{22,23}$. While all these situations have been widely documented, little is known about which online behaviors and which social media and communication platforms are most likely associated with negative and risky situations.

\subsection{Current study}

This study, seeking to explore predictors of adolescents' exposure to online risks, is guided by the following exploratory research questions: What demographic characteristics are associated with exposure to online risks? How is the use of social media and private messaging apps associated with exposure to online risks? Is adult supervision of adolescents' online activities a protective factor towards exposure to online risks?

\section{Materials and Methods}

\subsection{Study Design}

We implemented a cross-sectional study design by the use of an online survey, in four schools in Utah (USA), gathering data from students in 8th and 9th grade. The survey was implemented in April 2018 and parents were provided with opt-out forms one month before the start of data collection. Data were collected using the online survey platform Qualtrics. The survey link was distributed to the students by their teachers during class time - the survey took roughly twenty minutes to complete. The study protocol and instruments were approved by the Harvard T.H. Chan School of Public Health Institutional Review Board (IRB16-1757) as well as by the ethical committee of the school district where the study was implemented. The Helsinki ethics protocol was followed throughout the course of this study ${ }^{24}$. A copy of the survey instrument can be found in Appendix A.

\subsection{Dependent Variables}

To measure exposure to online risks, respondents were asked if they had ever experienced any of the following 8 situations: 1) Bullying or harassment by friends or acquaintances, 2) Getting involved in unwanted conversations in a chat room, social networking site, or on email, 3) Coming across sexual images or content, 4) Coming across images of violence, 5) Someone trying to sell me drugs or alcohol, 6) Someone using my photos in an inappropriate way, 7) A stranger trying to meet with me, 8) Coming across hate groups trying to convince me of their views. Some of these situations can be classified as content risk ( $\mathrm{q} 3$ and $q 4$ ), some others as contact risk (q1, q2, q6, q7, and q8), and one as commercial risk (q7). This dependent variable was studied in two ways: 1) using each of the eight situations as an outcome, 2) using the number of situations a student encountered as the outcome. We also created a dichotomous variable where $0=$ no situations encountered and 
$1=$ any number of situations encountered, to further study and confirm the relationship found in the previous analysis.

\subsection{Independent variables}

Independent variables included demographics (race, gender, and age), in addition to academic performance, use of social media and private messaging apps, and adult supervision. Academic performance was measured by frequency of grade type $(\mathrm{A}, \mathrm{A}-/ \mathrm{B}+, \mathrm{B}, \mathrm{B}-/ \mathrm{C}+$, and $\mathrm{C}$ or lower). Use of social media was measured by asking respondents which social media tool (i.e. YouTube, Snapchat, Instagram, etc.) they use and how frequently they use it, with answer options ranging from 1 (never) to 6 (all the time). A summative social media use score was created by dichotomizing the use of each social media platform used by the respondent into a dichotomous variable ( $1=$ daily use or higher, $0=$ less than daily use) and summing the attributed value across all fifteen platforms. Respondents were also asked if they used any private messaging apps, including Kik, Telegram, or WhatsApp, and if they used such apps more frequently than texting.

To further understand social media use and online behaviors, respondents were asked how many of their social media followers they knew in person, and how frequently they chatted with strangers while on social media. A similar question was asked about their friends' behaviors, under the assumption that they would be less likely to misreport friends' habits compared to their own. Additional questions focused on behaviors such as sharing personal information while on social media or chatting with strangers while playing online video games. Finally, respondents were asked about adult supervision, in particular, if their parents supervised their online activities, if anyone had ever talked to them about online safety, and if they had a trusted adult to ask for help in case they encountered an uncomfortable situation online.

\subsection{Statistical Analyses}

Simple and multiple logistic regression models were used to study how the independent variables were associated with the occurrence of each of the 8 situations identified as online risks. A Box-Tidwell procedure was used to confirm that aggregate social media use had a linear relationship to the log odds of each of the 8 dependent variables. Independent variables were included in the multiple models when a statistically significant association was found in the simple models ( $\mathrm{p}$-value $<0.05$ ). Gender, race, and age were included regardless of their significance in the final models because of theoretical relevance. Hosmer-Lemeshow tests were used to assess the goodness of fit of the multiple logistic regression models ${ }^{25}$. For the second dependent variable related to the number of situations the respondents experienced, a negative binomial regression model was fitted to the counts of the unsafe online situations. Pearson's chi-squared test of dispersion was used to assess the goodness of fit for the negative binomial model. We compared the fit of the negative binomial regression model to Poisson, zero-inflated Poisson, and zero-inflated negative binomial models using the Bayesian information criterion (BIC) to determine whether any of those distributional forms was more appropriate for this sample. For both logistic and negative binomial regressions, model misspecification was assessed using Pregibon's goodness-of-link test ${ }^{26}$. For models where the goodness-of-fit test failed, we tried to modify the set of covariates in the model to achieve a better fit as feasible. Data analysis was performed using Stata Statistical Software: Release 15.1. College Station, TX: StataCorp LLC.

\section{Results}

The response rate to the survey was $86 \%$ (767/897). This paper is based on the analysis of 733 students for which we had complete data on the dependent variable. Below we provide the sample characteristics based on demographics and academic performance, and descriptive statistics for social media and private messaging use, social media behaviors, adult supervision of online activities, and unsafe online situations experienced by the respondents. Following, we present the results of the multiple logistic regression models for the two dependent variables (each of the 8 unsafe situations and exposure to at least one situation). Finally, we present the results of the negative binomial regression model for the count of unsafe online scenarios.

\section{Table 1 about here}




\subsection{Sample characteristics and descriptive statistics}

Detailed descriptive statistics for the sample can be found in Table 1. We gathered data from a convenience sample of 733 individuals, the majority of whom were male $(51 \%)$. Major categories of race were: White (39\%), Hispanic (21\%), and mixed-race (10\%). The sample included students aged $14(41 \%), 15(58 \%)$, and $16(1 \%)$. Regarding academic performance, the majority of students reported receiving grades ranging between $\mathrm{A}-$ and $\mathrm{B}+(41 \%)$.

\subsubsection{Social media use and online behaviors}

Detailed descriptive statistics for the sample can be found in Table 1. Most participants reported using more than one social media platform on a daily basis $(85 \%)$, and $26 \%$ reported using three social media platforms daily. Only $14 \%$ of students had met all of their social media followers in person, the majority of them $(62 \%)$ reported that they had chatted with strangers on social media, and $62 \%$ reported they believe their friends did so as well. Thirty-one percent of respondents indicated they had shared personal information, such as their school or town name when posting on social media. Fourteen percent of students used private messaging apps, and among these students most frequently used WhatsApp (67\%), followed by Kik (37\%), and Telegram ( $9 \%$ ). The majority of participants played video games online (78\%), and among those who did, $59 \%$ reported that they chatted with someone they did not know while gaming. Regarding parents' supervision, the majority (52\%) of students reported that their parents did not install parental controls on their computer or other devices. The majority (69\%) of students reported they had a trusted adult they could ask for help if they experienced an online situation that made them feel uncomfortable. Finally, $95 \%$ of respondents reported that someone had spoken to them about online safety.

\subsubsection{Unsafe online situations}

\section{Table 2 about here}

Table 2 presents the detailed summary measures of each unsafe online event and the count of unsafe online events. The most frequently reported situation was coming across images of violence (32\%), followed by coming across sexual images or content (31\%), and bullying by friends or acquaintances (29\%). Twenty-six percent of respondents indicated they had been in an unwanted conversation in a chat room, social networking site, or on email. Only six percent of students reported someone using their photos in an inappropriate way. Fourteen percent of students indicated that someone had tried to sell them drugs or alcohol online. Seventeen percent of students reported experiencing a situation in which they encountered a stranger online who wanted to meet with them, and $14 \%$ of students reported coming across hate groups trying to convince them of their views. Overall, the distribution of the counts of unsafe online situations was skewed to the right with subjects reporting a mean of 1.7 events $(\mathrm{SD}=2)$ and a median of 1 (range $=0-8)$. The majority of the subjects $(40 \%)$ did not report experiencing any of the unsafe online situations listed in the survey.

\subsection{Logistic Regression Models}

\section{Table 3 about here}

Table 3 presents the results for the multiple logistic regression models for each unsafe online event. Simple logistic regression models were performed for each of the dichotomous dependent variables. BoxTidwell test results confirmed that our summative measure of overall social media use was linear to the log 
odds of each outcome $(p>0.05)$. Detailed results for the simple models can be found in Appendix B. The overall LR chi-square test statistics for the 8 multiple models exploring the association between the independent variables and each of the 8 online situations were significant $\left(\chi^{2}, p<0.01\right)$. Hosmer-Lemeshow Goodness of Fit test results confirmed that all models were a good fit for the data. Pregibon's link test did not indicate any model misspecification ( $\hat{y} p<0.05, \hat{y}^{2} p>0.05$ ), with the exception of the dependent variable someone trying to sell the respondent drugs. Below we provide a summary of key results for each situation and the counts of situations experienced.

\subsubsection{Online content risk}

Two of the eight unsafe online situations we investigated referred to exposure to harmful contents (content risk): 1) coming across sexual images or content and 2) coming across images of violence. Gender was predictive of exposure to both of these risks. Compared to males, females had twice the odds of coming across sexual images or content (OR=2, 95\% CI 1.4-2.9) and 1.9 times the odds of coming across images of violence (OR=1.9, 95\% CI 1.3-2.7). Chatting with a stranger while online was also a predictor for both of these content risks. Respondents who reported this behavior had $70 \%$ increased odds of coming across sexual content ( $\mathrm{OR}=1.7,95 \% \mathrm{CI} 1.1-2.5)$ and images of violence (OR=1.7, 95\% CI 1.1-2.6). Race was the only other variable that predictive of exposure to sexual images; white students had $50 \%$ increased odds of coming across the same content compared to non-white students (OR=1.5, 95\% CI 1-2.1).

Regarding the other content risk, age, academic performance, and social media use predicted coming across images of violence. Students aged 15 and older had 70\% increased odds of coming across images of violence (OR=1.7, 95\% CI 1.2-2.4). Students who received grades of B or lower had $60 \%$ increased odds of coming across images of violence, compared to those who had grades of $\mathrm{B}+$ or higher (OR=1.7, 95\% CI 1.2-2.4). Finally, the odds of coming across images of violence increased by $24 \%$ with each additional social media platform used by the respondent on a daily basis (OR=1.24, 95\% CI 1.08-1.43).

\subsubsection{Online contact risk}

Five out of the eight online unsafe situations we investigated referred to interactions with someone online that lead to an unsafe outcome (contact risk situations): 1) bullying and harassment by friends or acquaintances, 2) getting involved in unwanted conversations, 3) someone using the respondent's photos in an inappropriate way, 4) a stranger trying to meet with them, and 5) coming across hate groups trying to convince the respondent of their views. Chatting with a stranger while online was a predictor for all of the five contact risks. Respondents who reported this behavior had increased odds of exposure to the five contact risk situations. These increased odds ranged from $80 \%$ for having experienced unwanted conversations (OR=1.8, $95 \%$ C.I. 1.2-2.9), and for coming across hate groups ( $\mathrm{OR}=1.8,95 \%$ C.I. 1-3.2) to $350 \%$ for having had someone using the respondent's photos in an inappropriate way $(\mathrm{OR}=4.5,95 \%$ C.I. 1.5-13.3). Gender was associated with two of the five situations, with females having $70 \%$ increased odds of experiencing bullying or harassment while online (OR-1.7, 95\% 1.2-2.4) and 100\% increased odds of engaging in unwanted conversations ( $\mathrm{OR}=2,95 \%$ C.I 1.4-2.9). The number of social media platforms used by the respondent was associated with having experienced bullying or harassment the online space, the odds of experiencing bullying or harassment increased by $14 \%$ with each additional social media platform used by the respondent on a daily basis (OR=1.14, 95\% CI 1.01-1.28). Finally, the use of the private messaging app Kik was associated with $210 \%$ increased odds of having someone used the respondent's photos in an inappropriate way (OR=3.1, 95\% CI 1.19.2).

\subsubsection{Commercial risk}

One of the eight situations we investigated refers to the commercial risk: someone trying to sell the respondent drugs or alcohol. None of the independent variables resulted to be a significant predictor of this experience.

\subsection{Negative binomial model for number of types of unsafe online situations}


Table 4 displays the results of the negative binomial model for the number of types of unsafe online indicating the model accounted for any overdispersion in the data well. Also, Pregibon's link test did not indicate any model misspecification $\left(\hat{y} p<0.01, \hat{y}^{2} p=0.36\right.$ ). The model included the following predictors: age, gender, race, social media use, chatting with strangers on social media, the respondent's friends' habit of chatting with strangers on social media, parents' supervision of online activities, if anyone had ever talked to them about online safety and if they have a trusted adult to ask for help with unsafe online situations. The negative binomial model had a BIC of 2445.6 which was favorable when compared to the BIC from a Poisson (BIC=2646.4), zero-inflated Poisson (BIC=2487.5), and zero-inflated negative binomial $(B I C=2460.7)$ models with similar predictors.

In the negative binomial model, females had 1.5 times the incidence rate of experiencing different types of unsafe online situations compared to males (IRR=1.5, 95\% CI 1.3-1.9). Social media usage was also a significant predictor with each additional social media platform used on a daily basis associated with an $8 \%$ increase in the incidence rate of experiencing different types of unsafe online scenarios (IRR $=1.08,95 \%$ CI 1.011.15). Students who chatted with strangers on social media had 1.6 times the incidence of experiencing different types of unsafe online scenarios than those who did not (IRR=1.6, 95\% CI 1.3, 2.0). Lastly, the frequency in which the respondent's friends chatted with strangers on social media was a significant predictor $\left(\chi^{2}(\mathrm{df})=14.6(3), p=0.002\right)$. This was driven by significantly higher incidence rates of experiencing different types of unsafe online scenarios for students whose friends "sometimes" or "often" chatted with strangers on social media compared to students who did not know if their friends chatted with strangers with an IRR of 1.5 (95\% CI 1.2-1.9) and 1.6 (95\% CI 1.2-2.1), respectively.

Similar results were obtained in logistic regression models for our dichotomized variable for exposure to any unsafe online situation (see Table 3). Results from these analyses similarly indicated that gender (OR=2.0, $95 \%$ CI 1.4-2.7), social media use (OR=1.16, 95\% CI 1.01-1.32), chatting with strangers online (OR=2.3, 95\% CI 1.6-3.4), and friends chatting with strangers online $\left(\chi^{2}(\mathrm{df})=11.8(3), p=0.008\right)$ was significantly associated with exposure to unsafe events online.

\section{Discussion and Conclusions}

The goal of this study was to explore the predictors of adolescents' exposure to online risks, with a specific focus on the demographic characteristics that are associated with exposure to online risks, which social media and private messaging apps are associated with exposure to online risks and how/if adult supervision of adolescents' online activities a protective factor towards exposure to online risks. Overall, our findings support the important role that certain individual characteristics (namely gender and age) play as a risk factor for exposure to risk online. Findings from our study show how some children appear to be particularly "at risk" when online; being more likely to encounter risky or uncomfortable situations when on the internet. In particular, our study points to the existence of gender disparities in the exposure to online risks, with girls being more likely than boys to encounter online risks. The role of gender is inevitably complex and multifaceted, but our data show that such disparities seem to be independent of other online behaviors such as the amount of time spent online or type of social media platform being used, suggesting how social factors might play a role including the potential for girls being the target of harassment, violence and sexual abuse. In addition to this, the type and duration of social media activity did increase some forms of online risk. Finally, there was little evidence of parental supervision as a protective factor.

Overall, the theoretical importance of this paper is to focus on the role of the individual as a precursor to being exposed to risk online. At the global level, we are increasingly focused on the harm caused by material accessed on the Internet. Policymakers, academics, politicians, mental health, and medical professionals seek to understand the processes online that govern the relationship between internet use and risk. While the majority of research has explored the effect of the Internet on the individual - such as the induced feeling of anonymity -27 , increasingly, research is exploring the role of the user on the likelihood that they engage in or 
are exposed to risky material online ${ }^{28,29}$. This research reinforces this interactionist perspective of online risk in that risk is the result of an interaction between the nature of "being online" with the pre-existing characteristics and personality of the user.

In addition to this, these findings also support the idea of differential risk in that while certain characteristics have a domain-general effect on risk, increasing the chance of engaging in risky behavior across a range of behaviors, others increase risk in a refined (or domain-specific) manner. For example, while being female increases the risks of being exposed to bullying, violent and sexual images, unwanted conversations, and at least one risky event, using the private messaging app Kik only increased the chances of an individual's photos being used inappropriately. From a theoretical perspective, what this encourages is the need to better differentiate the relationship between characteristics, and or social media use and the specific type of risk that someone is engaged in. From a behaviorist standpoint, extant literature has shown that broad patterns of behavior reflect different fundamental incentives to human action ${ }^{30,31}$. What this means then is that when it comes to online crime, we need to unpack the underlying incentives that guide both engagement with certain forms of online behavior and the certain risks that may stem from this.

These findings thus have important implications for the prevention of online harm. The question of coping is important as part of a wider shift from a technologically determinist discourse (of what the internet "does" to children) in favor of recognizing the importance of building children's digital resilience. Encountering risk could in itself also represent an opportunity - to become more resilient, more digitally literate, and less vulnerable to online risks ${ }^{32}$. Sustained efforts are required from a variety of stakeholders, including families, schools, and technology industries in order to effectively safeguard children online in a dynamic technological and social media landscape. Thus, it is important to identify vulnerabilities that expose some children to higher risks so as to focus prevention efforts on those who will most benefit from them.

Educational initiatives are then tasked with developing programming for youth to address these underlying influences associated with online threats. These initiatives should be designed to develop the critical capability in children to recognize and mitigate the risks encountered by also learning how to selfregulate their behavior and seek help when needed. Children learning how to identify and interpret the impact and potential repercussions of various online behaviors can be influential in the overall safeguarding of youth online; among these potential risks, our study highlighted those posed by chatting with strangers, excessive use of social media platforms, and private messaging apps, and the development of both the technical and emotional competence to self-regulate online behaviors and deal with uncomfortable situations.

Initiatives that build knowledge and awareness about online risks are necessary, as is better awareness of existing disparities in exposure to risks. What this research can lend to the building and framing of educational internet safety initiatives is how to talk about and approach particular risks with students. Each risk online should be approached and talked uniquely and originally, avoiding "one-size-fit-all" narratives that assume that all risks and the nature of such risks are the same. For example, the above findings show that the risks associated with certain online messaging apps are not all-encompassing, but rather narrowly associated with the inappropriate use of photos. Furthermore, chatting with strangers on social media has an array of potential associated risks, whereas the single risk significantly associated with chatting with strangers while gaming is strangers wanting to meet in-person. Understanding this connection and the association of certain platforms, actions, and risks can help inform education programming to give a more direct educational lesson to students to help with improving their self-regulated behaviors, necessary skills, and understanding of the potential risks around them. For educational organizations and schools, these findings should be taken into consideration when building lessons and their contents; learning examples and worksheets can better reflect certain risks and their association with certain behaviors. Additionally, these should inform the way targeted programming for those at-risk should be handled. This data shows that girls are disproportionately exposed to risky or uncomfortable situations, therefore calling on these prevention programs to address these concerns with catered content. Simple changes to existing curricula might include the changing of the subject in particular examples to reflect a more accurate depiction of the research above, or more large-scale changes might be to offer further educational programming for those populations that are shown to be at higher risk of certain exposures.

With the continued increase of youth internet use, the need for reflective, impactful internet safety education is becoming more crucial. Schools are the main means by which a society can address digital safety 
and citizenship issues for all children within a structured learning environment. To achieve optimal success in this area, it requires teacher training and curriculum materials that are age and gender appropriate as well as more research on the factors associated with online vulnerability.

In considering the findings of this study, several limitations are acknowledged. Since our data were crosssectional, we lack information on the temporal ordering of our variables, and we cannot assume causality. As a non-random convenience sample, it is important to acknowledge that these results are not necessarily generalizable outside of the sample, and that selection bias may have also influenced our reported results. Furthermore, as some of the exposures and outcomes could be perceived as negative, there is potential for social desirability bias to influence students' responses.

Its limitations notwithstanding, our results provide critical information to practitioners involved in the development of educational initiatives by building a profile of potentially risky online behaviors, as well as allow them to tailor their initiatives to meet the needs of more vulnerable populations. The results presented in this manuscript also provide a platform for future longitudinal research to further investigate the magnitude of risk associated with these behaviors. We note that the measurement of online risk has largely escaped empirical investigation - to our knowledge, there is no extant screening tool for exposure to online risk that has had its psychometric properties evaluated - future research should aim to address this gap. Our results should be understood under the growing understanding that exposure to unsafe material online should be understood as a matter of if, not when, and as such, we recommend that future research should investigate how individuals engage with risky online content and the psychological processes which may influence exposure.

Supplementary Materials: The questionnaire used for data collection is included as a supplementary file. The data gathered during the course of the project are available upon request, due to research subjects' privacy considerations, via the national public repository of data Criminal Justice Data (NACJD), hosted by the Inter-university Consortium for Political and Social Research (ICPSR; at the University of Michigan), and can be found at the following link: https://www.icpsr.umich.edu/web/NACJD/studies/37338.

Author Contributions: E.S. Developed the study design, drafted the introduction, and provided feedback on the discussion and conclusions of the manuscript. N.H. and M.S. Performed the statistical analyses and drafted the methods, results, and tables. N.S. and T.C. drafted the discussion and conclusions. All authors have read and agreed to the published version of the manuscript.

Funding Sources: Research reported in this publication was supported by the National Institute of Justice under award number 2016-ZA-BX-K001 Evaluation of the Peer to Peer (P2P): Challenging Extremism Initiative and award number 20182A-CX-0002 Operation250: An Evaluation of a Primary Prevention Campaign focused on Online Safety and Risk Assessment. The content is solely the responsibility of the authors and does not necessarily represent the official views of the National Institutes of Justice.

Declaration of Conflicts of Interest: The authors declare no conflict of interests.

Acknowledgments: The authors of this manuscript would like to acknowledge the work of Marcia A. Testa and Valentina Baccolini on the initial stages of data analysis and manuscript development.

\section{References}

1. George, M. J.; Jensen, M. R.; Russell, M. A.; Gassman-Pines, A.; Copeland, W. E.; Hoyle, R. H.; Odgers, C. L., Young Adolescents' Digital Technology Use, Perceived Impairments, and Well-Being in a Representative Sample. J Pediatr 2020, 219, 180-187.

2. UNICEF Guidelines for Industry on Child Online Protection; UNICEF - Office of Research: 2015.

3. Gámez-Guadix, M.; Borrajo, E.; Almendros, C., Risky online behaviors among adolescents: Longitudinal relations among problematic Internet use, cyberbullying perpetration, and meeting strangers online. J Behav Addict 2016, 5 (1), 100-107.

4. UNICEF Growing up in a connected world; UNICEF Office of Research: 2019.

5. Green, N., Outwardly Mobile: Young People and Mobile Technologies: The Social Context of Personal Communication Technology. 2003; pp 201-217.

6. Ling, R., The Mobile Connection: The Cell Phone's Impact on Society. Morgan Kaufmann Publishers Inc.: 2004. 
7. Geser, H., Pre-teen cell phone adoption: Consequences for later patterns of phone usage and involvement. In Sociology of the Mobile Phone, Sociology in Switzerland Online Publications Zurich: 2006.

8. UNICEF The state of the world's children 2017. Children in a digital world.; United Nations Children's Fund: 2017.

9. Schilder, J. D.; Brusselaers, M. B.; Bogaerts, S., The Effectiveness of an Intervention to Promote Awareness and Reduce Online Risk Behavior in Early Adolescence. J Youth Adolesc 2016, 45 (2), 286-300.

10. Nesi, J.; Prinstein, M. J., Using Social Media for Social Comparison and Feedback-Seeking: Gender and Popularity Moderate Associations with Depressive Symptoms. J Abnorm Child Psychol 2015, 43 (8), 1427-1438.

11. Barry, C. T.; Sidoti, C. L.; Briggs, S. M.; Reiter, S. R.; Lindsey, R. A., Adolescent social media use and mental health from adolescent and parent perspectives. Journal of Adolescence 2017, 61, 1-11.

12. Casey, B. J., Beyond simple models of self-control to circuit-based accounts of adolescent behavior. Annu Rev Psychol 2015, 66, 295-319.

13. Shulman, E. P.; Smith, A. R.; Silva, K.; Icenogle, G.; Duell, N.; Chein, J.; Steinberg, L., The dual systems model: Review, reappraisal, and reaffirmation. Dev Cogn Neurosci 2016, 17, 103-17.

14. Seabrook, E. M.; Kern, M. L.; Rickard, N. S., Social Networking Sites, Depression, and Anxiety: A Systematic Review. JMIR Ment Health 2016, 3 (4), e50.

15. Spies Shapiro, L. A.; Margolin, G., Growing up wired: social networking sites and adolescent psychosocial development. Clin Child Fam Psychol Rev 2014, 17 (1), 1-18.

16. Subrahmanyam, K.; Greenfield, P., Online communication and adolescent relationships. Future Child 2008, 18 (1), $119-46$.

17. Underwood, M. K.; Ehrenreich, S. E., The power and the pain of adolescents' digital communication: Cyber victimization and the perils of lurking. Am Psychol 2017, 72 (2), 144-158.

18. Valkenburg, P. M.; Peter, J., Online communication among adolescents: an integrated model of its attraction, opportunities, and risks. J Adolesc Health 2011, 48 (2), 121-7.

19. Best, P.; Manktelow, R.; Taylor, B., Online communication, social media and adolescent wellbeing: A systematic narrative review. Children and Youth Services Review 2014, 41, 27-36.

20. Sasson, H.; Mesch, G., Gender Differences in the Factors Explaining Risky Behavior Online. J Youth Adolesc 2016, $45(5), 973-85$.

21. Vannucci, A.; Simpson, E. G.; Gagnon, S.; Ohannessian, C. M., Social media use and risky behaviors in adolescents: A meta-analysis. Journal of Adolescence 2020, 79, 258-274.

22. Pacheco, E.; Melhuish, N., New Zealand Children's Experiences of Online Risks and Their Perceptions of Harm. Evidence From Ngā Taiohi Matihiko O Aotearoa - New Zealand Kids Online. SSRN Electronic Journal 2020.

23. Ofcom Children and parents: media use and attitudes report 2017; Ofcom - Research and Data Department: 2017.

24. World Medical Association Declaration of Helsinki: ethical principles for medical research involving human subjects. Jama 2013, 310 (20), 2191-4.

25. Hosmer Jr, D. W.; Lemeshow, S.; Sturdivant, R. X., Applied logistic regression. John Wiley \& Sons: 2013; Vol. 398.

26. Pregibon, D., Goodness of Link Tests for Generalized Linear Models. Journal of the Royal Statistical Society. Series C (Applied Statistics) 1980, 29 (1), 15-14.

27. Suler, J., The Online Disinhibition Effect. CyberPsychology \& Behavior 2004, 7 (3), 321-326.

28. Palmieri, M.; Shortland, N.; McGarry, P., Personality and online deviance: The role of reinforcement sensitivity theory in cybercrime. Computers in Human Behavior 2021, 120, 106745.

29. Harriman, N.; Shortland, N.; Su, M.; Cote, T.; Testa, M. A.; Savoia, E., Youth Exposure to Hate in the Online Space: An Exploratory Analysis. International Journal of Environmental Research and Public Health 2020, 17 (22), 8531.

30. Youngs, D., How does crime pay? The differentiation of criminal specialisms by fundamental incentive. Journal of Investigative Psychology and Offender Profiling 2006, 3 (1), 1-19.

31. Bandura, A., Social foundations of thought and action: A social cognitive theory. Prentice-Hall, Inc: Englewood Cliffs, NJ, US, 1986; p xiii, 617-xiii, 617.

32. Schoon, I., Risk and Resilience. Adaptations in Changing Times. Risk and Resilience: Adaptations in Changing Times 2006, 1-222. 
Table 1 - Students' Social media use

\begin{tabular}{|c|c|c|c|}
\hline Chat with strangers on social media & $\mathbf{N}(\%)$ & Connections know in person & $\mathbf{N}(\%)$ \\
\hline I don't have a social media account & $57(8 \%)$ & I don't have a social media account & $82(11 \%)$ \\
\hline Never & $222(30 \%)$ & I am not sure how many & $130(18 \%)$ \\
\hline I did it a few times & $215(29 \%)$ & Some of them & $149(20 \%)$ \\
\hline Sometimes & $154(21 \%)$ & Most of them & $272(37 \%)$ \\
\hline Often & $85(12 \%)$ & All of them & $100(14 \%)$ \\
\hline $\begin{array}{l}\text { Share personal information on social } \\
\text { media }\end{array}$ & $\mathbf{N}(\%)$ & $\begin{array}{l}\text { Friends chat with strangers on social } \\
\text { media }\end{array}$ & $\mathbf{N}(\%)$ \\
\hline I don't have a social media account & $76(10 \%)$ & I don't know & $195(27 \%)$ \\
\hline Never & $433(59 \%)$ & Never & $84(11 \%)$ \\
\hline Sometimes & $191(26 \%)$ & Sometimes & $319(44 \%)$ \\
\hline Often & $33(5 \%)$ & Often & $135(18 \%)$ \\
\hline Talked to about online safety & $\mathbf{N}(\%)$ & $\begin{array}{l}\text { Use private messaging more than } \\
\text { texting }\end{array}$ & $\mathrm{N}(\%)$ \\
\hline Never & $35(5 \%)$ & No & $581(79 \%)$ \\
\hline Sometimes & $280(38 \%)$ & Yes & $78(11 \%)$ \\
\hline Often & $418(57 \%)$ & Not sure & $74(10 \%)$ \\
\hline Trusted adult & $\mathbf{N}(\%)$ & Chat with strangers while gaming & $\mathbf{N}(\%)$ \\
\hline No & $79(11 \%)$ & I do not play video games & $97(13 \%)$ \\
\hline Yes & $507(69 \%)$ & Never & $260(36 \%)$ \\
\hline Not sure & $121(16 \%)$ & Sometimes & $215(29 \%)$ \\
\hline It depends on the situation & $26(4 \%)$ & Often & $161(22 \%)$ \\
\hline $\begin{array}{l}\text { Presence of parental controls on } \\
\text { computer or other devices }\end{array}$ & $\mathbf{N}(\%)$ & Play video games & $\mathbf{N}(\%)$ \\
\hline No & $378(52 \%)$ & Never & $163(22 \%)$ \\
\hline Yes & $236(32 \%)$ & Often & $289(40 \%)$ \\
\hline Not sure & $119(16 \%)$ & Sometimes & $281(38 \%)$ \\
\hline Use Kik & $\mathbf{N}(\%)$ & $\begin{array}{l}\text { Number of social media platforms } \\
\text { used daily }\end{array}$ & N (\%) \\
\hline No & $696(95 \%)$ & 0 & $112(15 \%)$ \\
\hline Yes & $37(5 \%)$ & 1 & $87(12 \%)$ \\
\hline Use Telegram & $\mathbf{N}(\%)$ & 2 & $165(23 \%)$ \\
\hline No & $724(99 \%)$ & 3 & $188(26 \%)$ \\
\hline Yes & $9(1 \%)$ & 4 & $111(15 \%)$ \\
\hline Use WhatsApp & $\mathbf{N}(\%)$ & 5 & $52(7 \%)$ \\
\hline No & $666(91 \%)$ & 6 or more & $18(2 \%)$ \\
\hline Yes & $67(9 \%)$ & & \\
\hline
\end{tabular}


Table 2 - Unsafe Online Situations

\begin{tabular}{|c|c|}
\hline Situation & $\mathbf{N}(\%)$ \\
\hline Bullying or harassment by friends or acquaintances & $214(29 \%)$ \\
\hline $\begin{array}{l}\text { Getting involved in unwanted conversations in a chat } \\
\text { room, social networking site or on email }\end{array}$ & $187(26 \%)$ \\
\hline Coming across sexual images or content & $224(31 \%)$ \\
\hline Coming across images of violence & $236(32 \%)$ \\
\hline Someone trying to sell me drugs or alcohol & $101(14 \%)$ \\
\hline Someone using my photos in an inappropriate way & $42(6 \%)$ \\
\hline A stranger trying to meet with me & $125(17 \%)$ \\
\hline $\begin{array}{l}\text { Coming across hate groups trying to convince me of their } \\
\text { views }\end{array}$ & $102(14 \%)$ \\
\hline Number of Situations Encountered & $\mathbf{N}(\%)$ \\
\hline 0 & $291(40 \%)$ \\
\hline 1 & $147(20 \%)$ \\
\hline 2 & $87(12 \%)$ \\
\hline 3 & $86(12 \%)$ \\
\hline 4 & $45(6 \%)$ \\
\hline 5 & $34(5 \%)$ \\
\hline 6 & $17(2 \%)$ \\
\hline 7 & $8(1 \%)$ \\
\hline 8 & $18(2 \%)$ \\
\hline Mean (SD) & $1.7(2)$ \\
\hline Median (Range) & $1(0-8)$ \\
\hline
\end{tabular}


Table 3 - Multiple Logistic Regression Models

\begin{tabular}{|c|c|c|c|c|c|c|c|c|c|}
\hline Covariate & $\begin{array}{c}\text { OS1 } \\
\text { Bullying } \\
\end{array}$ & $\begin{array}{c}\text { OS 2 } \\
\text { Unwanted } \\
\text { conversations }\end{array}$ & $\begin{array}{c}\text { OS } 3 \\
\text { Sexual images }\end{array}$ & $\begin{array}{c}\text { OS } 4 \\
\text { Violent images }\end{array}$ & $\begin{array}{c}\text { OS } 5 \\
\text { Drugs \& alcohol } \\
\end{array}$ & $\begin{array}{c}\text { OS } 6 \\
\text { Photos used } \\
\text { inappropriately } \\
\end{array}$ & $\begin{array}{c}\text { OS } 7 \\
\text { Stranger }\end{array}$ & $\begin{array}{c}\text { OS } 8 \\
\text { Hate Groups }\end{array}$ & $\begin{array}{l}\text { At least one } \\
\text { unsafe event }\end{array}$ \\
\hline & \multicolumn{9}{|c|}{ Continuous and Dichotomous Predictors - OR (95\% CI) } \\
\hline Age (15 and older vs. 14) & $\begin{array}{c}1.1 \\
(0.8-1.6)\end{array}$ & $\begin{array}{c}1.2 \\
(0.8-1.8)\end{array}$ & $\begin{array}{c}1.2 \\
(0.8-1.7)\end{array}$ & $\begin{array}{c}1.7 \\
(1.2-2.4)^{* *}\end{array}$ & $\begin{array}{c}1.4 \\
(0.8-2.2)\end{array}$ & $\begin{array}{c}0.8 \\
(0.4-1.6)\end{array}$ & $\begin{array}{c}1.5 \\
(0.9-2.2)\end{array}$ & $\begin{array}{c}1.2 \\
(0.8-2)\end{array}$ & $\begin{array}{c}1.3 \\
(0.9-1.8) \\
\end{array}$ \\
\hline Gender (Female vs. Male) & $\begin{array}{c}1.7 \\
(1.2-2.4)^{* *}\end{array}$ & $\begin{array}{c}2 \\
(1.4-2.9)^{* *}\end{array}$ & $\begin{array}{c}2 \\
(1.4-2.9)^{* * *}\end{array}$ & $\begin{array}{c}1.9 \\
\left(1.3-2.77^{* *}\right.\end{array}$ & $\begin{array}{c}1.4 \\
(0.9-2.3)\end{array}$ & $\begin{array}{c}1.8 \\
(0.9-3.9)\end{array}$ & $\begin{array}{c}1.6 \\
(1-2.7)\end{array}$ & $\begin{array}{c}1.6 \\
(1-2.5)\end{array}$ & $\begin{array}{c}2 \\
(1.4-2.7)^{* * *}\end{array}$ \\
\hline Race (White vs. Non-White) & $\begin{array}{c}1.3 \\
(0.9-1.9) \\
\end{array}$ & $\begin{array}{c}1.1 \\
(0.8-1.7)\end{array}$ & $\begin{array}{c}1.5 \\
(1-2.1)^{*}\end{array}$ & $\begin{array}{c}1.1 \\
(0.8-1.6)\end{array}$ & $\begin{array}{c}1.2 \\
(0.7-1.9)\end{array}$ & $\begin{array}{c}0.9 \\
(0.4-1.9)\end{array}$ & $\begin{array}{c}0.7 \\
(0.5-1.1)\end{array}$ & $\begin{array}{c}0.8 \\
(0.5-1.3)\end{array}$ & $\begin{array}{c}1.2 \\
(0.9-1.7) \\
\end{array}$ \\
\hline $\begin{array}{l}\text { Grades (B and lower vs. B+ and } \\
\text { higher) }\end{array}$ & - & - & - & $\begin{array}{c}1.6 \\
(1.1-2.3)^{*}\end{array}$ & - & - & - & - & - \\
\hline Kik Use (Yes vs. No) & $\begin{array}{c}1.8 \\
(0.9-3.9) \\
\end{array}$ & - & $\begin{array}{c}1.9 \\
(0.9-4)\end{array}$ & - & $\begin{array}{c}1.2 \\
(0.5-3) \\
\end{array}$ & $\begin{array}{c}3.1 \\
(1.1-9.2)^{*}\end{array}$ & $\begin{array}{c}1.6 \\
(0.7-3.8) \\
\end{array}$ & $\begin{array}{c}2.1 \\
(0.9-4.9) \\
\end{array}$ & $\begin{array}{c}1.4 \\
(0.6-3.2)\end{array}$ \\
\hline WhatsApp Use (Yes vs. No) & - & - & - & - & - & - & $\begin{array}{c}1.2 \\
(0.6-2.3)\end{array}$ & - & $\begin{array}{c}1.2 \\
(0.6-2.2)\end{array}$ \\
\hline Telegram Use (Yes vs. No) & - & - & - & - & - & - & - & - & - \\
\hline $\begin{array}{l}\text { Chatting with strangers on social } \\
\text { media (Any Frequency of } \\
\text { Communication vs. Never/I don't } \\
\text { have a social media account) }\end{array}$ & $\begin{array}{c}1.9 \\
(1.3-2.8)^{* *}\end{array}$ & $\begin{array}{c}1.8 \\
(1.2-2.9)^{*}\end{array}$ & $\begin{array}{c}1.7 \\
(1.1-2.5)^{*}\end{array}$ & $\begin{array}{c}1.7 \\
(1.2-2.6)^{*}\end{array}$ & $\begin{array}{c}1.7 \\
(1-3.1)\end{array}$ & $\begin{array}{c}4.5 \\
(1.5-13.3)^{*}\end{array}$ & $\begin{array}{c}2.1 \\
(1.2-3.4)^{*}\end{array}$ & $\begin{array}{c}1.8 \\
(1-3.2)^{*}\end{array}$ & $\begin{array}{l}2.3 \\
(1.6-3.4)^{* *}\end{array}$ \\
\hline $\begin{array}{l}\text { Sharing Personal Information on } \\
\text { Social Media (Any Frequency of } \\
\text { Sharing vs. Never/I don't have a } \\
\text { social media account) }\end{array}$ & - & $\begin{array}{c}1.2 \\
(0.8-1.8)\end{array}$ & - & - & - & $\begin{array}{c}1.7 \\
(0.8-3.5)\end{array}$ & $\begin{array}{c}1.3 \\
(0.8-2)\end{array}$ & - & $\begin{array}{c}1.3 \\
(0.9-1.9)\end{array}$ \\
\hline $\begin{array}{l}\text { Playing video games (Any } \\
\text { Frequency of Use vs. Never) }\end{array}$ & - & - & - & - & - & - & $\begin{array}{c}0.9 \\
(0.5-1.6)\end{array}$ & - & - \\
\hline $\begin{array}{l}\text { Chatting with strangers while } \\
\text { playing video games (Any } \\
\text { Frequency of Communication vs. } \\
\text { Never/I don't plav video games) }\end{array}$ & - & - & - & - & - & - & $\begin{array}{c}0.5 \\
(0.3-0.8)^{*}\end{array}$ & - & - \\
\hline $\begin{array}{l}\text { Having someone talk to you about } \\
\text { online safety (continuous) }\end{array}$ & - & - & - & $\begin{array}{c}1.2 \\
(0.9-1.6)\end{array}$ & - & - & - & - & $\begin{array}{c}1.2 \\
(0.9-1.6)\end{array}$ \\
\hline \multirow[t]{2}{*}{ Social Media Use (continuous) } & $\begin{array}{c}1.14 \\
(1.01-1.28)^{*} \\
\end{array}$ & $\begin{array}{c}1.07 \\
(0.93-1.24) \\
\end{array}$ & $\begin{array}{c}1.11 \\
(0.97-1.27)\end{array}$ & $\begin{array}{c}1.24 \\
(1.08-1.42)^{* *}\end{array}$ & $\begin{array}{c}1.13 \\
(0.95-1.35) \\
\end{array}$ & $\begin{array}{c}1.11 \\
(0.86-1.43) \\
\end{array}$ & $\begin{array}{c}1.01 \\
(0.87-1.18) \\
\end{array}$ & $\begin{array}{c}1.02 \\
(0.86-1.22) \\
\end{array}$ & $\begin{array}{c}1.16 \\
(1.01-1.32)^{*}\end{array}$ \\
\hline & \multicolumn{9}{|c|}{ Categorical Predictors with 3+ Categories - Chi-Squared (df); $p$-value } \\
\hline $\begin{array}{l}\text { Use Private Messaging Apps More } \\
\text { than Texting (categorical) }\end{array}$ & - & - & - & - & - & - & - & - & - \\
\hline $\begin{array}{l}\text { Amount of followers known in } \\
\text { person (categorical) }\end{array}$ & - & $\begin{array}{l}3.52(4) ; \\
p=0.474\end{array}$ & $\begin{array}{l}3.14(4) ; \\
p=0.534\end{array}$ & $\begin{array}{l}7.24(4) ; \\
p=0.124\end{array}$ & $\begin{array}{l}5.57(4) ; \\
p=0.216\end{array}$ & - & - & $\begin{array}{c}5.28(4) ; \\
p=0.26\end{array}$ & $\begin{array}{l}1.08(4) ; \\
p=0.897\end{array}$ \\
\hline $\begin{array}{l}\text { Frequency that friends chat with } \\
\text { strangers on social media } \\
\text { (categorical) }\end{array}$ & - & $\begin{array}{l}7.5(3) ; \\
p=0.056\end{array}$ & $\begin{array}{r}10.43) ; \\
p=0.015\end{array}$ & $\begin{array}{l}9.45(3) ; \\
p=0.024\end{array}$ & $\begin{array}{l}6.75(3) \\
p=0.077\end{array}$ & - & $\begin{array}{l}6.83(3) ; \\
p=0.078\end{array}$ & $\begin{array}{l}10.7(3) \\
p=0.014\end{array}$ & $\begin{array}{l}11.8(3) \\
p=0.008\end{array}$ \\
\hline $\begin{array}{l}\text { Having a trusted adult to ask for } \\
\text { help with unsafe online situations } \\
\text { (categorical) }\end{array}$ & $\begin{array}{l}6.78 \text { (3); } \\
p=0.079 \\
\end{array}$ & $\begin{array}{l}3.91(3) ; \\
p=0.271\end{array}$ & - & - & - & $\begin{array}{l}4.35(3) ; \\
p=0.226\end{array}$ & - & - & - \\
\hline
\end{tabular}




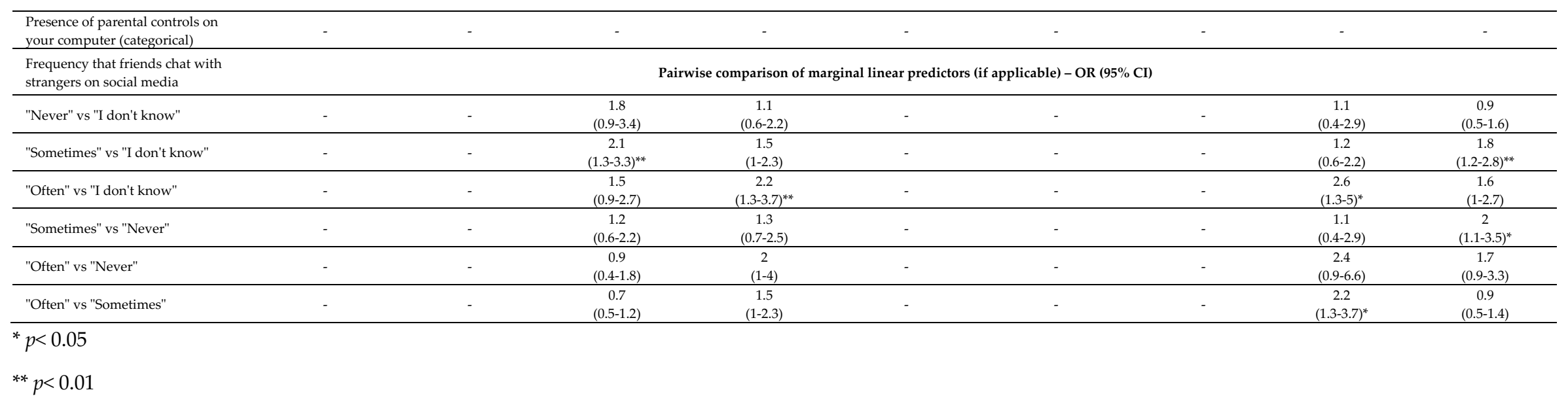

OS 1 - Bullying or harassment by friends or acquaintances

OS 2 - Getting involved in unwanted conversations in a chat room, social networking site or on email

OS 3 - Coming across sexual images or content

OS 4 - Coming across images of violence

OS 5 - Someone trying to sell me drugs or alcohol

OS 6 - Someone using my photos in an inappropriate way

OS 7 - A stranger trying to meet with me

OS 8 - Coming across hate groups trying to convince me of their views 
Table 4 - Negative Binomial Model for Counts of Types of Unsafe Online Situations

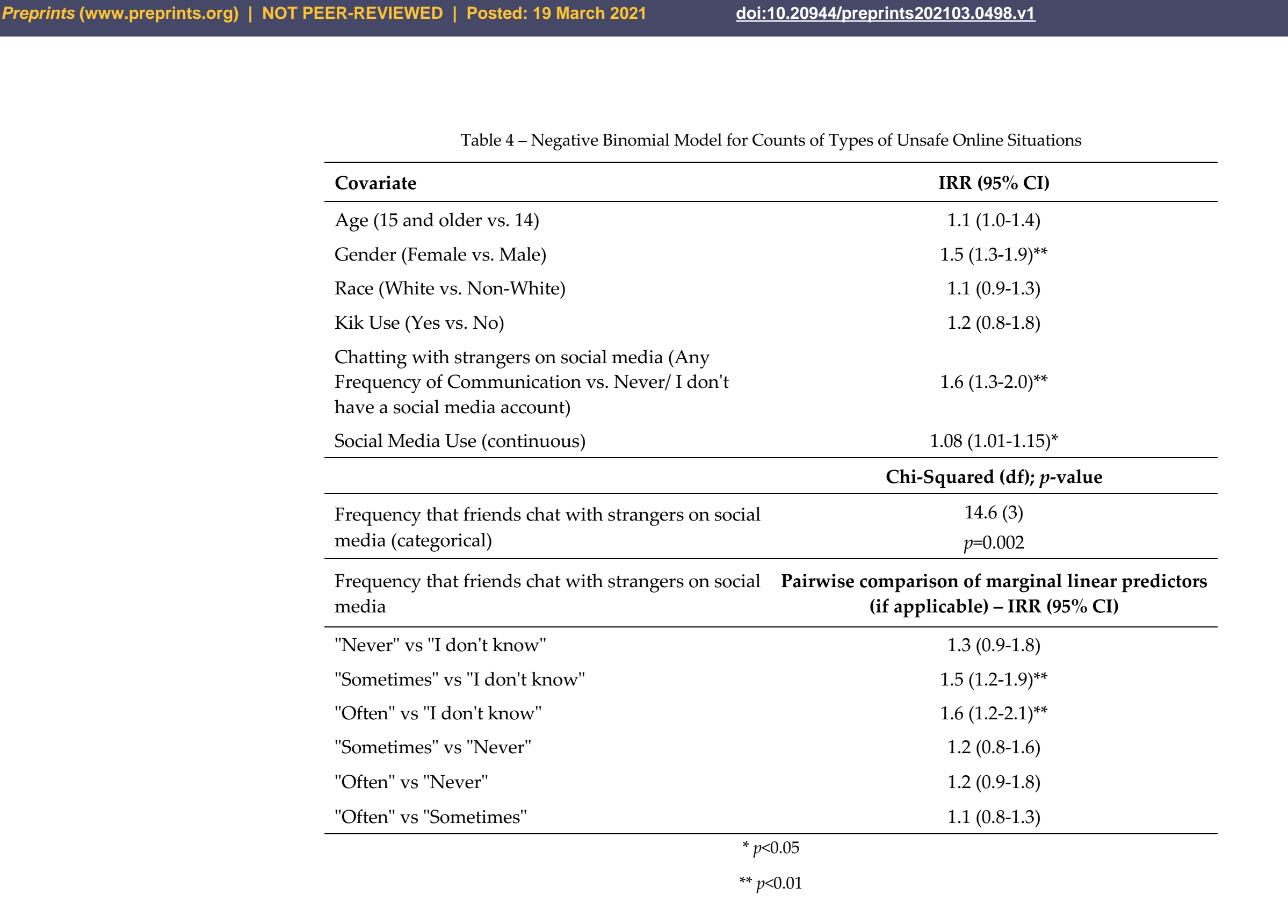

.

(1)

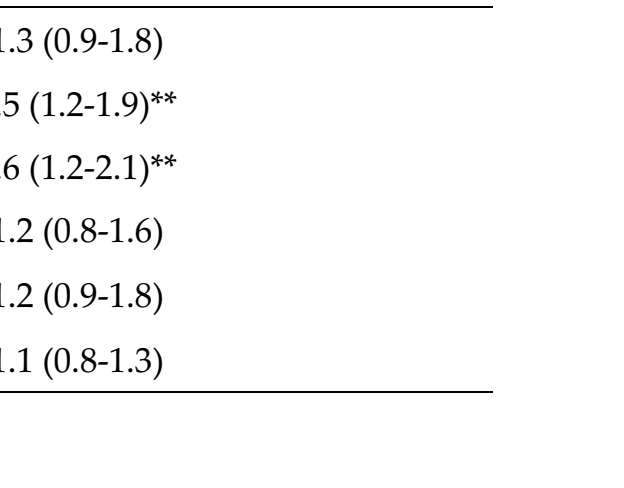

